\title{
MISO-Type Voltage-Mode Universal Biquadratic Filter Using Single Universal Voltage Conveyor
}

\author{
Kanhaiya Lal Pushkar¹, Kavya Gupta ${ }^{2}$ \\ ${ }^{1}$ Department of Electronics and Communication Engineering, Maharaja Agrasen Institute of Technology, New Delhi, India \\ ${ }^{2}$ Electronics and Communication Engineering Cell, Radiance Edutech ${ }^{\mathrm{TM}}$, DDA Market, Delhi, India \\ Email: klpushkar17@gmail.com, kavyagpt17@gmail.com
}

How to cite this paper: Pushkar, K.L. and Gupta, K. (2017) MISO-Type Voltage-Mode Universal Biquadratic Filter Using Single Universal Voltage Conveyor. Circuits and Systems, 8, 227-236. https://doi.org/10.4236/cs.2017.89015

Received: August 21, 2017

Accepted: September 22, 2017

Published: September 25, 2017

Copyright $\odot 2017$ by authors and Scientific Research Publishing Inc. This work is licensed under the Creative Commons Attribution International License (CC BY 4.0).

http://creativecommons.org/licenses/by/4.0/

\begin{abstract}
A universal biquadratic filter using single universal voltage conveyor (UVC), two resistors and two capacitors is presented in this paper. The proposed structure has three inputs and one output and can realize all the five standard biquadratic filters: low-pass (LP), high-pass (HP), band-pass (BP), band-reject (BR) and all-pass (AP) from the same circuit configuration. The presented universal filter offers low active and passive sensitivities. SPICE (Version 16.5) simulation results using $0.18 \mu \mathrm{m}$ TSMC technology have been included.
\end{abstract}

\section{Keywords}

Universal Voltage Conveyor, Voltage-Mode, Filter, Analog Circuit Design

\section{Introduction}

There is a growing interest in the design of single-input multi-output (SIMO) or multi-input single-output (MISO) voltage-mode (VM) or current-mode (CM) universal filter configurations, due to their flexibility and versatility for practical applications [1]. In literature [2]-[8], filter configurations employing different active building blocks/devices (such as current differencing transconductance amplifier (CDTA), current differencing buffered amplifier (CDBA), modified current feedback operational amplifier (MCFOA), current feedback operational amplifier (CFOA) and voltage differencing voltage transconductance amplifier (VDVTA)) have been presented over the past few years. Multifunction filter structures have been presented in [9], where structures employing three UVCs could realize only three basic filters (i.e. LP, HP, and BP). In [10], authors have proposed three multi-function filter structures employing: $i)$ Three UVCs which can realize three basic filters i.e. LP, HP, and BP. ii) Two UVCs which can realize 
four basic filters i.e. LP, HP, BP and, AP. iii) Single UVC which can realize four basic filters i.e. LP, HP, BP and, AP.

Filter structures presented in references [9] [10] are unable to realize all the basic biquadratic filter functions from single topology (i.e. LP, HP, BP, BR and $\mathrm{AP})$. Therefore, the purpose of this paper is to propose a new universal VM biquad with three inputs and one output, which can realize all basic standard second order filter functions, namely: LP, HP, BP, BR and AP without changing the circuit topology. Workability of the proposed filter has been established by SPICE (Version 16.5) simulations using $0.18 \mu \mathrm{m}$ TSMC technology.

\section{Proposed Filter Configuration}

The symbolic representation and equivalent circuit model of the UVC are shown in Figure 1(a) and Figure 1(b) respectively. The UVC is a 6-port active element with one voltage input $x$, two difference current inputs $\left(y^{+}, y^{-}\right)$, two mutually inverse voltage outputs $\left(z^{+}, z^{-}\right)$, and one auxiliary port $w$. Using standard notations, the relationship between port currents and voltages of a six port UVC is given by the following equations.

$$
I_{x}=I_{y^{+}}-I_{y^{-}}, V_{w}=V_{y^{+}}=V_{y^{-}}, V_{z^{+}}=V_{x}, V_{z^{-}}=-V_{x}, I_{w}=0
$$

A routine circuit analysis (assuming ideal UVC) of Figure 2 gives the follow-

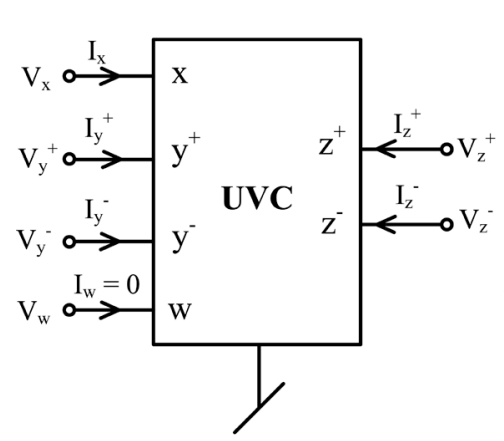

(a)

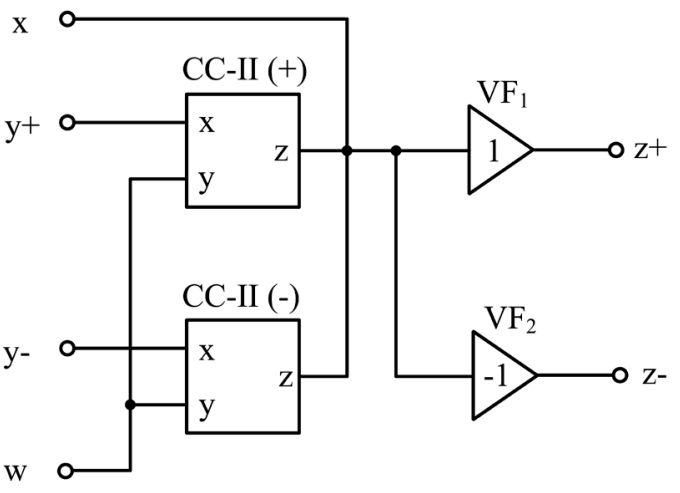

(b)

Figure 1. (a) Symbolic representation of UVC; (b) Equivalent circuit model of UVC [11].

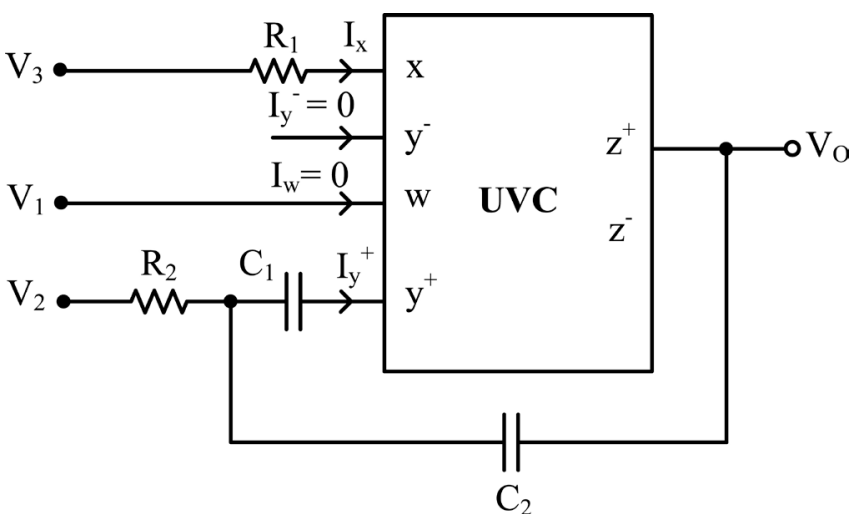

Figure 2. The proposed voltage-mode universal biquadratic filter. 
ing expression for the output voltage in terms of input voltages:

$$
V_{o}=\frac{V_{1}\left\{s^{2}+s\left(\frac{1}{C_{2} R_{2}}\right)\right\}-V_{2} s\left(\frac{1}{C_{2} R_{2}}\right)+V_{3}\left\{\frac{1}{R_{1}}\left(s\left(\frac{1}{C_{1}}+\frac{1}{C_{2}}\right)+\frac{1}{C_{1} C_{2} R_{2}}\right)\right\}}{s^{2}+s\left\{\frac{1}{R_{1}}\left(\frac{1}{C_{1}}+\frac{1}{C_{2}}\right)\right\}+\frac{1}{R_{1} R_{2} C_{1} C_{2}}}
$$

From Equation (2), all standard filter functions (LP, HP, BP, BR and AP) can be realized (for $R_{1}=R_{2}=R$ and $C_{1}=C_{2}=C$ ):

1) If $V_{3}=V_{\text {in }}, V_{2}=2 V_{\text {in }}$ and $V_{1}=0$ (grounded), then low pass filter can be realized.

$$
\left.T(s)\right|_{L P}=\frac{\frac{1}{R^{2} C^{2}}}{D(s)}
$$

2) If $V_{1}=V_{2}=V_{\text {in }}$ and $V_{3}=0$ (grounded), then high pass filter can be realized

$$
\left.T(s)\right|_{H P}=\frac{s^{2}}{D(s)}
$$

3) If $V_{2}=V_{\text {in }}$ and $V_{1}=V_{3}=0$ (grounded), then band pass filter can be realized.

$$
\left.T(s)\right|_{B P}=\frac{-s\left(\frac{1}{R C}\right)}{D(s)}
$$

4) If $V_{3}=V_{1}=V_{\text {in }}$ and $V_{2}=3 V_{\text {in }}$, then band reject filter can be realized.

$$
\left.T(s)\right|_{B R}=\frac{s^{2}+\frac{1}{R^{2} C^{2}}}{D(s)}
$$

5) If $V_{3}=V_{1}=V_{\text {in }}$ and $V_{2}=5 V_{\text {in }}$, then all pass filter can be realized.

$$
\left.T(s)\right|_{A P}=\frac{s^{2}-s\left(\frac{2}{R C}\right)+\frac{1}{R^{2} C^{2}}}{D(s)}
$$

where: $D(s)=s^{2}+s\left(\frac{2}{R C}\right)+\frac{1}{R^{2} C^{2}}$

The expressions for natural frequency $\left(\omega_{0}\right)$, quality factor $\left(Q_{0}\right)$ and bandwidth $(B W)$ are given by:

$$
\omega_{0}=\sqrt{\frac{1}{R_{1} R_{2} C_{1} C_{2}}}, Q_{0}=\frac{\sqrt{\frac{R_{1} C_{1} C_{2}}{R_{2}}}}{C_{1}+C_{2}}, B W=\frac{1}{R_{1}}\left(\frac{1}{C_{1}}+\frac{1}{C_{2}}\right)
$$

From Equation (3), it can be observed that after adjusting $B W$ by $R_{1}, \omega_{0}$ can independently be controlled through $R_{2}$. Furthermore, it is seen that no inversion of the input signal(s) is required in any of the five filter realizations.

In the ideal case, the various sensitivities of $\omega_{0}$ and $B W$ with respect to $R_{1}, R_{2}$, 
$C_{1}$, and $C_{2}$ are found to be:

$$
\begin{gathered}
S_{C_{1}}^{\omega_{0}}=S_{C_{2}}^{\omega_{0}}=S_{R_{1}}^{\omega_{0}}=S_{R_{2}}^{\omega_{0}}=-\frac{1}{2} \\
S_{C_{1}}^{B W}=-\left(\frac{1}{1+\frac{C_{1}}{C_{2}}}\right), S_{C_{2}}^{B W}=-\left(\frac{1}{1+\frac{C_{2}}{C_{1}}}\right), S_{R_{1}}^{B W}=-1, S_{R_{2}}^{B W}=0
\end{gathered}
$$

\section{Non-Ideal Analysis and Sensitivity Performance}

Model of UVC including parasitic elements is shown in the Figure 3 [12].

Taking into account, the non-idealities of UVC, the relationship of the terminal voltages and currents in Equation (1) can be rewritten as:

$$
I_{x}=\alpha_{1} I_{y^{+}}-\alpha_{2} I_{y^{-}}, V_{y^{+}}=\delta_{1} V_{w}, V_{y^{-}}=\delta_{2} V_{w}, V_{z^{+}}=\gamma_{1} V_{x}, V_{z^{-}}=\gamma_{2} V_{x}, I_{w}=0
$$

where $\alpha_{j}=1-\varepsilon_{i j}$ and $\delta_{j}=1-\varepsilon_{v 1 j}, \quad \gamma_{j}=1-\varepsilon_{v 2 j}$ for $j=1,2$. Here $\varepsilon_{i j}\left(\left|\varepsilon_{i j}\right| \ll 1\right)$ and $\varepsilon_{v 1 j}, \quad \varepsilon_{v 2 j} \varepsilon_{i j}\left(\left|\varepsilon_{v 1 j}\right|,\left|\varepsilon_{v 2 j}\right| \ll 1\right)$ represent the current and voltage tracking errors of the UVC, respectively. The parasitic present on the low impedance ports $\left(y^{+}, y^{-}, z^{+}, z^{-}\right)$is quite low as compared to the resistances on the other ports $(w$ and $x$ ) [13]. After considering the parasitic of UVC in the proposed structure, shown in Figure 4, the expression for output voltage in terms of input voltages is given as follows:

$$
\begin{gathered}
V_{0}=\frac{\alpha_{1} \delta_{1} \gamma_{1} V_{1}\left(s^{2} C_{1} C_{2}+s \frac{C_{1}}{R_{2}}\right)-\alpha_{1} \gamma_{1} V_{2}\left(s \frac{C_{1}}{R_{2}}\right)+\gamma_{1} V_{3}\left(s\left(\frac{C_{1}+C_{2}}{R_{1}}\right)+\frac{1}{R_{1} R_{2}}\right)}{s^{2}\left(\alpha_{1} \gamma_{1} C_{1} C_{2}+C_{1} C_{x}+C_{2} C_{x}\right)+s\left(\frac{C_{1}+C_{2}}{R_{1}}+\frac{C_{1}+C_{2}}{R_{x}}+\frac{C_{x}}{R_{2}}\right)+\frac{1}{R_{2}}\left(\frac{1}{R_{1}}+\frac{1}{R_{x}}\right)} \\
\omega_{0}=\sqrt{\frac{R_{1}+R_{x}}{R_{1} R_{2} R_{x}\left(\alpha_{1} \gamma_{1} C_{1} C_{2}+C_{1} C_{x}+C_{2} C_{x}\right)}}
\end{gathered}
$$

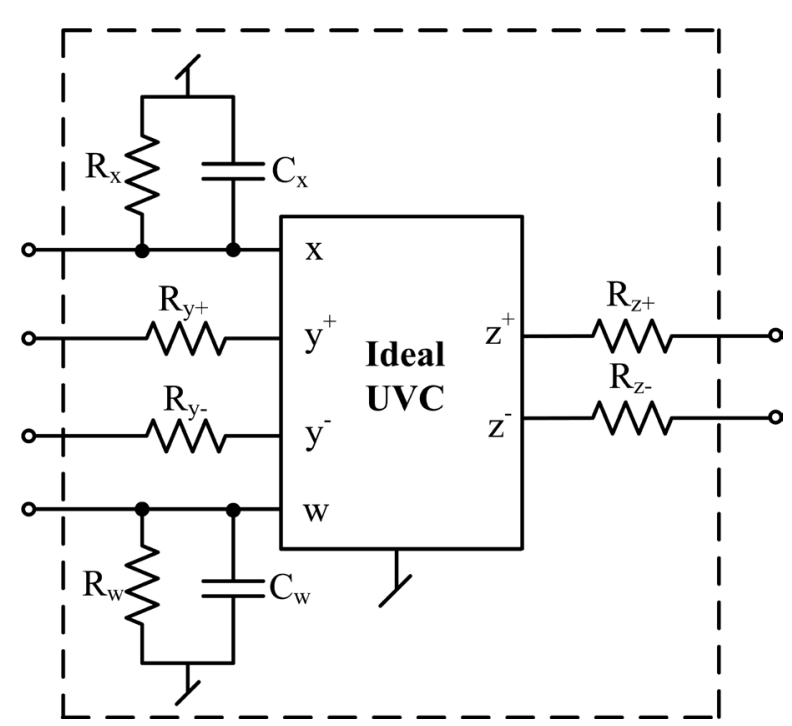

Figure 3. Non-ideal model of UVC. 


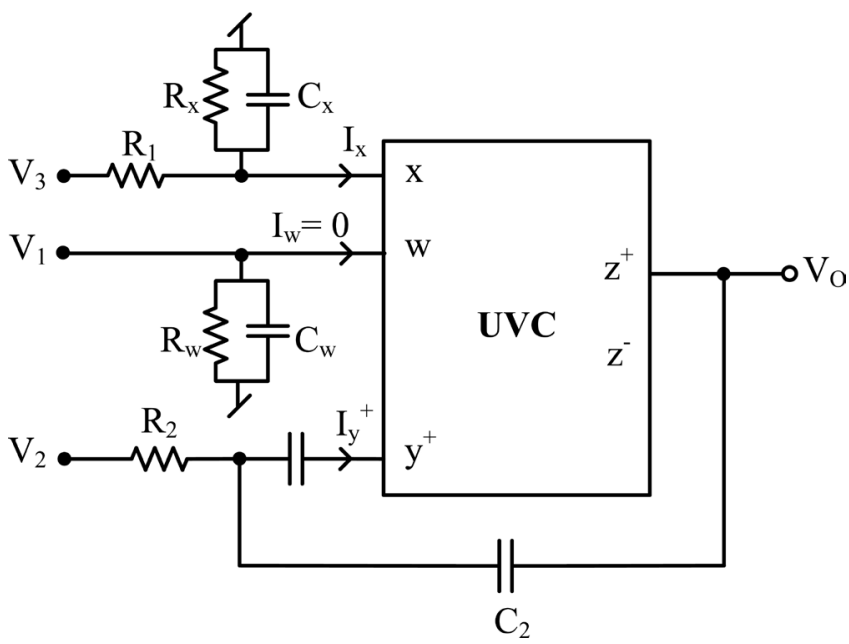

Figure 4. The proposed biquadratic filter considering the parasitic.

$$
B W=\frac{\left(C_{1}+C_{2}\right)\left(\frac{1}{R_{x}}+\frac{1}{R_{1}}\right)+\frac{C_{x}}{R_{2}}}{\alpha_{1} \gamma_{1} C_{1} C_{2}+C_{1} C_{x}+C_{2} C_{x}}
$$

Its active and passive sensitivities can be found as:

$$
\begin{aligned}
& S_{C_{1}}^{\omega_{0}}=-\frac{1}{2}\left(\frac{1}{1+\frac{C_{2} C_{x}}{\alpha_{1} \gamma_{1} C_{1} C_{2}+C_{1} C_{x}}}\right), S_{C_{2}}^{\omega_{0}}=-\frac{1}{2}\left(\frac{1}{1+\frac{C_{1} C_{x}}{\alpha_{1} \gamma_{1} C_{1} C_{2}+C_{2} C_{x}}}\right) \\
& S_{C_{x}}^{\omega_{0}}=-\frac{1}{2}\left(\frac{1}{1+\frac{\alpha_{1} \gamma_{1} C_{1} C_{2}}{C_{2} C_{x}+C_{1} C_{x}}}\right), S_{R_{1}}^{\omega_{0}}=-\frac{1}{2}\left(\frac{1}{1+\frac{R_{1}}{R_{x}}}\right), S_{R_{2}}^{\omega_{0}}=-\frac{1}{2}, S_{R_{x}}^{\omega_{0}}=-\frac{1}{2}\left(\frac{1}{1+\frac{R_{x}}{R_{1}}}\right) \\
& S_{C_{1}}^{B W}=-\frac{C_{1}\left(\left(\alpha_{1} \gamma_{1} C_{2}^{2}\right)\left(\frac{1}{R_{x}}+\frac{1}{R_{1}}\right)+\frac{\alpha_{1} \gamma_{1} C_{2} C_{x}}{R_{2}}+\frac{C_{x}^{2}}{R_{2}}\right)}{\left(\left(C_{1}+C_{2}\right)\left(\frac{1}{R_{x}}+\frac{1}{R_{1}}\right)+\frac{C_{x}}{R_{2}}\right)\left(\alpha_{1} \gamma_{1} C_{1} C_{2}+C_{1} C_{x}+C_{2} C_{x}\right)} \\
& S_{C_{2}}^{B W}=-\frac{C_{2}\left(\left(\alpha_{1} \gamma_{1} C_{1}^{2}\right)\left(\frac{1}{R_{x}}+\frac{1}{R_{1}}\right)+\frac{\alpha_{1} \gamma_{1} C_{1} C_{x}}{R_{2}}+\frac{C_{x}^{2}}{R_{2}}\right)}{\left(\left(C_{1}+C_{2}\right)\left(\frac{1}{R_{x}}+\frac{1}{R_{1}}\right)+\frac{C_{x}}{R_{2}}\right)\left(\alpha_{1} \gamma_{1} C_{1} C_{2}+C_{1} C_{x}+C_{2} C_{x}\right)} \\
& S_{C_{x}}^{B W}=-\frac{C_{x}^{2}\left(\frac{C_{1} C_{x}}{R_{2}}+\frac{\alpha_{1} \gamma_{1} C_{1} C_{2}}{R_{2}}-C_{2}\left(C_{1}+C_{2}\right)\left(\frac{1}{R_{x}}+\frac{1}{R_{1}}\right)\right)}{\left(\left(C_{1}+C_{2}\right)\left(\frac{1}{R_{x}}+\frac{1}{R_{1}}\right)+\frac{C_{x}}{R_{2}}\right)\left(\alpha_{1} \gamma_{1} C_{1} C_{2}+C_{1} C_{x}+C_{2} C_{x}\right)} \\
& S_{R_{1}}^{B W}=\frac{-1}{1+\frac{\left(\left(C_{1}+C_{2}\right) R_{2}+C_{x} R_{x}\right) R_{1}}{\left(C_{1}+C_{2}\right) R_{2} R_{x}}}, S_{R_{2}}^{B W}=\frac{-1}{1+\frac{\left(C_{1}+C_{2}\right)\left(R_{x}+R_{1}\right) R_{2}}{C_{x} R_{1} R_{x}}}
\end{aligned}
$$




$$
S_{R_{\chi}}^{B W}=\frac{-1}{1+\frac{\left(\left(C_{1}+C_{2}\right) R_{2}+C_{x} R_{1}\right) R_{x}}{\left(C_{1}+C_{2}\right) R_{2} R_{1}}}
$$

Considering the typical values of various parasitic capacitance $C_{x}=17.41 \mathrm{pF}$ and parasitic resistance $R_{x}=378.73 \mathrm{k} \Omega, \alpha_{1}=\alpha_{2}=\delta_{1}=\delta_{2}=\gamma_{1}=-\gamma_{2}=1 \quad$ [14] along with $C_{1}=C_{2}=100 \mathrm{pF}, R_{1}=R_{2}=100 \mathrm{k} \Omega$, the various sensitivities are found to be $S_{C_{1}}^{\omega_{0}}=S_{C_{2}}^{\omega_{0}}=-0.4365, S_{C_{x}}^{\omega_{0}}=-0.497, S_{R_{1}}^{\omega_{0}}=-0.375, S_{R_{2}}^{\omega_{0}}=-0.5$, $S_{R_{X}}^{\omega_{0}}=-0.125$ which are all quite low.

\section{Simulation Results}

To validate its theoretical analysis, the presented biquadratic filter is verified by SPICE simulations. The voltage and current selected for CMOS implementation of UVC are $\pm 1.9 \mathrm{~V}$ and $100 \mu \mathrm{A}$, respectively. CMOS implementation of universal voltage conveyor shown in Figure 5 and the aspect ratios of MOSFETs used in Figure 5 are given in Table 1 [15]. The passive elements are chosen as $C_{1}=C_{2}=100 \mathrm{pF}, R_{1}=R_{2}=100 \mathrm{k} \Omega$. The natural frequency $\left(\omega_{0}\right)$ and bandwidth $(B W)$ of the proposed filter for the selected passive elements are $15.99 \mathrm{kHz}$ and $31.8 \mathrm{kHz}$ respectively. Figure 6 shows the magnitude response of the proposed biquadratic filter. Figure 7 and Figure 8 show the magnitude and phase responses of all pass filter respectively. A comparison with other previously known MISO-type biquads using different active building blocks has been given

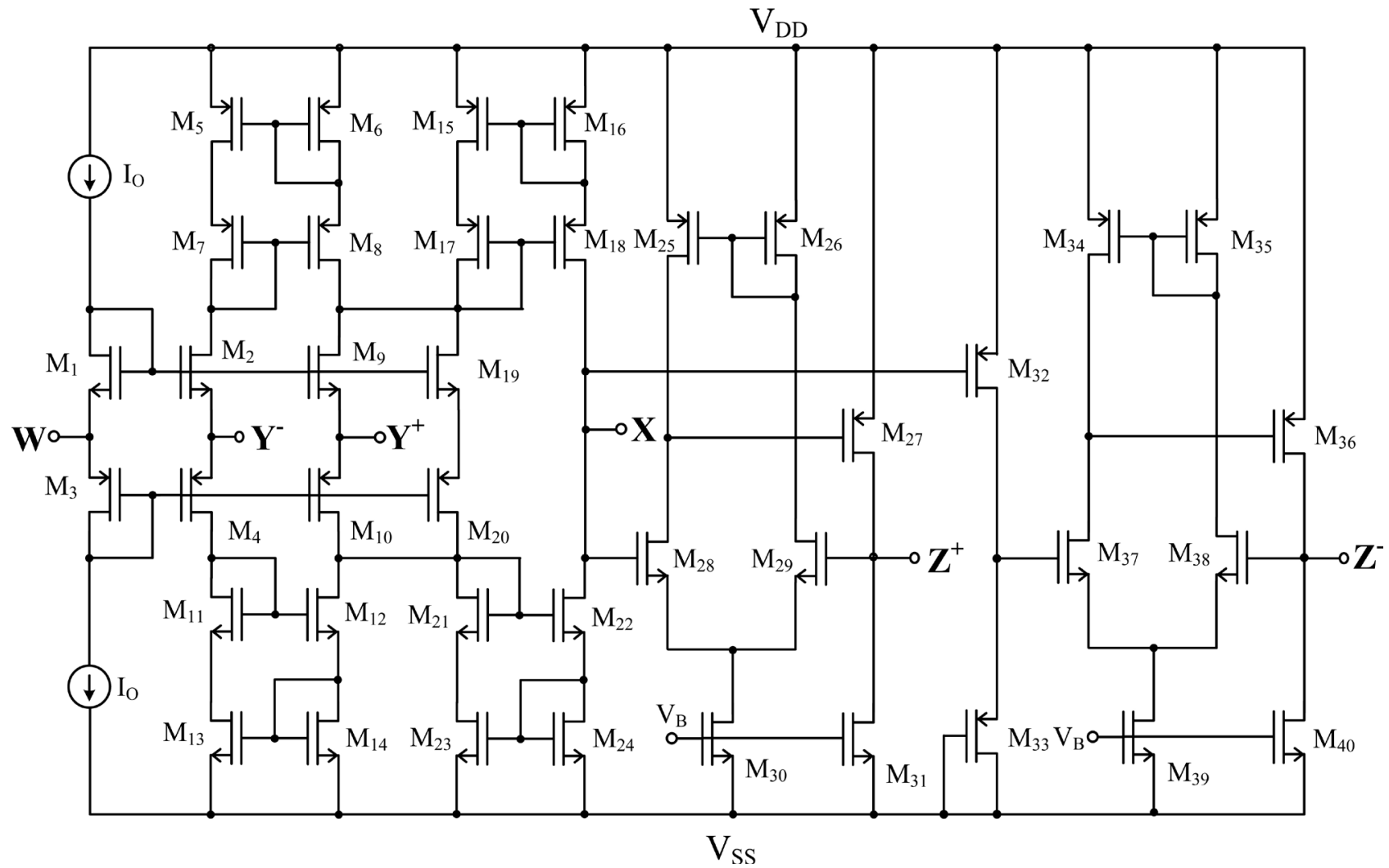

Figure 5. CMOS implementation of UVC, $\mathrm{V}_{\mathrm{DD}}=-\mathrm{V}_{\mathrm{SS}}=1.9 \mathrm{~V}, \mathrm{I}_{\mathrm{o}}=100 \mu \mathrm{A}$. 
Table 1. The aspect ratios (W/L) of MOSFETs used in Figure 5.

\begin{tabular}{cc}
\hline PMOS transistors & $\mathrm{W}(\mu \mathrm{m}) / \mathrm{L}(\mu \mathrm{m})$ \\
\hline M5 - M8, M10, M15 - M18, M20 & $14.0 / 0.7$ \\
M3, M4 & $28 / 0.7$ \\
M25, M26, M34, M35 & $4.0 / 0.5$ \\
M27, M36 & $10.0 / 0.5$ \\
M32, M33 & $2.1 / 1.0$ \\
\hline NMOS transistors MI, M2 & $\mathrm{W}(\mu \mathrm{m}) / \mathrm{L}(\mu \mathrm{m})$ \\
\hline M1, M2 & $14.0 / 0.7$ \\
M9, M11 - M14, M19, M21 - M24 & $28 / 0.7$ \\
M28, M29, M37, M38 & $0.8 / 05$ \\
M30, M31, M39, M40 & $10 / 0.5$ \\
\hline
\end{tabular}

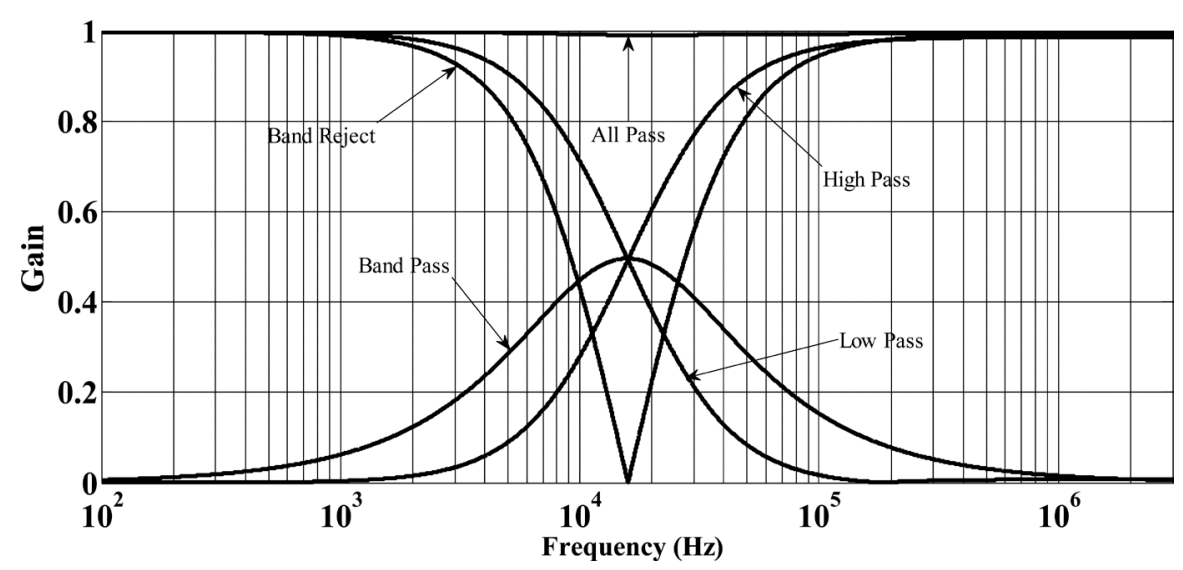

Figure 6. Frequency response of the proposed biquad filter.

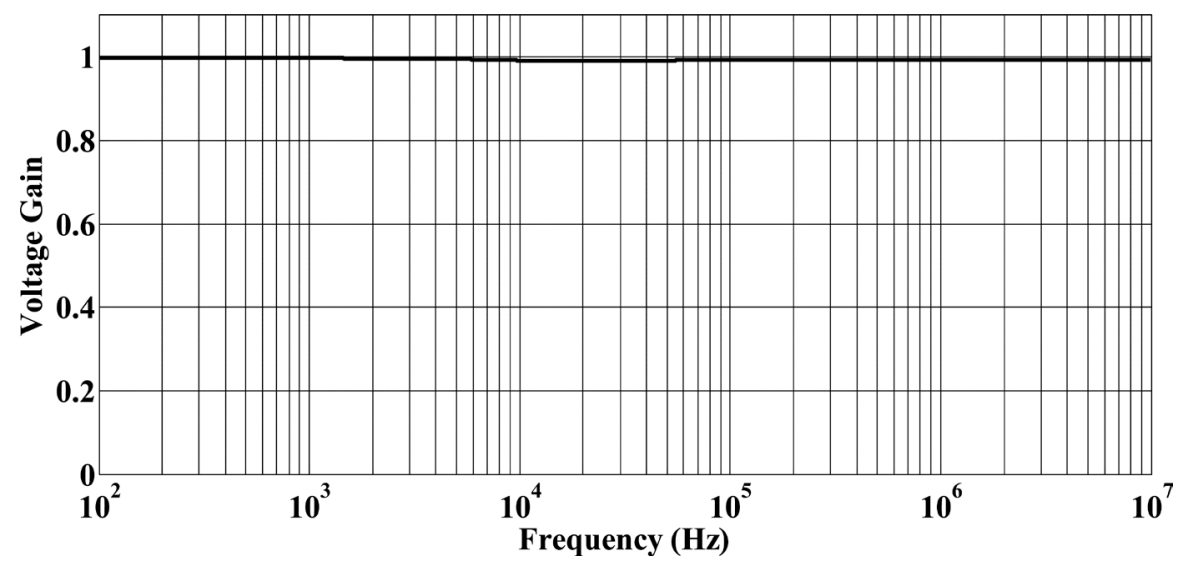

Figure 7. Frequency response of all-pass filter.

in Table 2. CMOS UVC was implemented using $0.18 \mu \mathrm{m}$ TSMC CMOS model parameters [16].

\section{Conclusion}

A New voltage-mode MISO-type universal biquadratic filter configuration is 


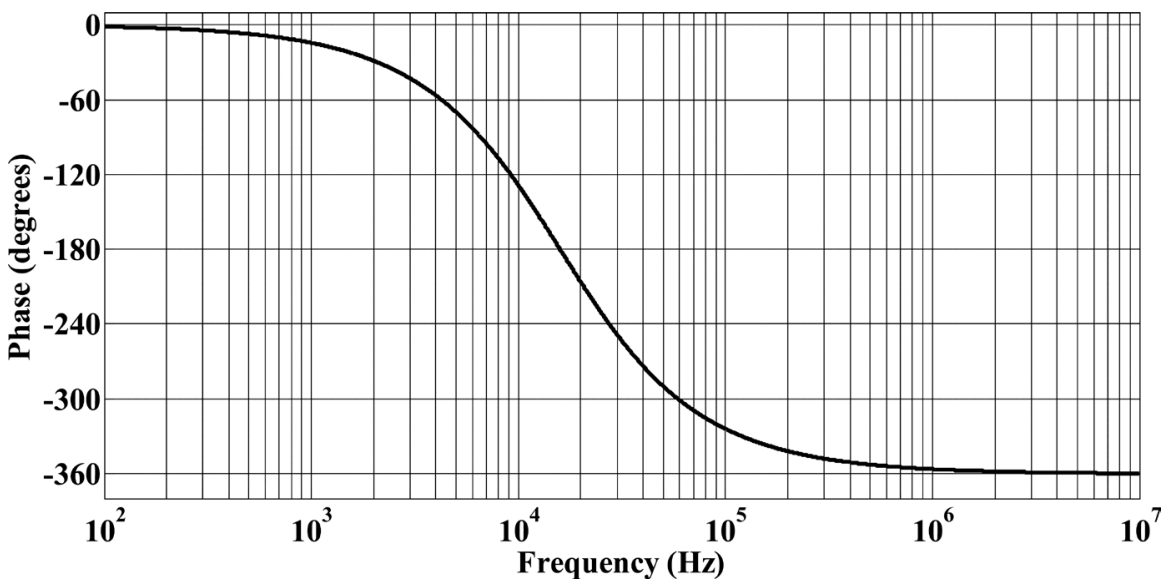

Figure 8. Phase response of all-pass filter.

Table 2. A comparison with other previously known MISO-type biquads using different active building blocks.

\begin{tabular}{|c|c|c|c|c|c|}
\hline \multirow{2}{*}{ Reference } & \multirow{2}{*}{$\begin{array}{l}\text { No. of active } \\
\text { components }\end{array}$} & \multicolumn{2}{|c|}{$\begin{array}{l}\text { No. of passive } \\
\text { components }\end{array}$} & \multirow{2}{*}{$\begin{array}{l}\text { Requirement of } \\
\text { matching } \\
\text { condition(s) }\end{array}$} & \multirow{2}{*}{$\begin{array}{c}\text { Number of } \\
\text { standard filters } \\
\text { realized }\end{array}$} \\
\hline & & Capacitors & Resistors & & \\
\hline [2] & 1 (CDTA) & 2 & 3 & Yes & Five \\
\hline [3] & 1 (CDBA) & 4 & 4 & Yes & Five \\
\hline [4] & 1 (CDBA) & 2 & 4 & Yes & Five \\
\hline [5] & 1 (MCFOA) & 2 & 3 & Yes & Five \\
\hline [6] & 1 (CFA) & 2 & 2 & Yes & Five \\
\hline [7] & 1 (CFA) & 2 & 3 & Yes & Five \\
\hline [8] & 1(VDVTA) & 1 & 2 & No & Four \\
\hline [9] & 3 (UVC) & 2 & 5 & No & $\begin{array}{c}\text { Three } \\
(\mathrm{LP}, \mathrm{HP}, \mathrm{BP})\end{array}$ \\
\hline \multirow{3}{*}{ [10] } & 3 (UVC) & 2 & 5 & No & $\begin{array}{c}\text { Three } \\
(\mathrm{LP}, \mathrm{HP}, \mathrm{BP})\end{array}$ \\
\hline & 2 (UVC) & 2 & 3 & No & $\begin{array}{c}\text { Four } \\
(\mathrm{LP}, \mathrm{HP}, \mathrm{BP}, \mathrm{AP})\end{array}$ \\
\hline & 1 (UVC) & 2 & 2 & No & $\begin{array}{c}\text { Four } \\
(\mathrm{LP}, \mathrm{HP}, \mathrm{BP}, \mathrm{AP})\end{array}$ \\
\hline Proposed & 1 (UVC) & 2 & 2 & YES & Five \\
\hline
\end{tabular}

proposed. The presented filter circuit employs single UVC with a minimum number of passive components, two capacitors, and two resistors. By proper selection of input voltages, all the basic second order filters can be realized, which are LP, HP, BP, BR, and AP without altering the circuit structure. Simulation results using $0.18 \mu \mathrm{m}$ TSMC CMOS technology have been presented to confirm the workability of the proposed new universal biquadratic filter. Limitations of the proposed structure are: i) matching of passive components and ii) reduced gain of band pass filter. For future scope matching conditions could be removed, 
further unity gain of the band pass filter can be achieved.

\section{References}

[1] Pushkar, K.L., Bhaskar, D.R. and Prasad, D. (2013) Voltage-Mode New Universal Biquad Filter Configuration Using a Single VDIBA. Circuits, Systems, and Signal Processing, 33, 275-285. https://doi.org/10.1007/s00034-013-9625-0

[2] Prasad, D., Bhaskar, D.R. and Singh, A.K. (2009) Multi-Function Biquad Using Single Current Differencing Transconductance Amplifier. Analog Integrated Circuits and Signal Processing, 61, 309-313. https://doi.org/10.1007/s10470-009-9310-1

[3] Keskin, A.U. (2006) Multi-Function Biquad Using Single CDBA. Electrical Engineering, 88, 353-356. https://doi.org/10.1007/s00202-004-0289-4

[4] Bashir, S.A. and Shah, N.A. (2012) Voltage Mode Universal Filter Using Current Differencing Buffered Amplifier as an Active Device. Circuits and Systems, 3, 1-4. https://doi.org/10.4236/cs.2012.33038

[5] Herencsar, N., Koton, J., Vrba, K. and Cicekoglu, O. (2009) Single UCC-N1B 0520 Device as a Modified CFOA and Its Application to Voltage- and Current-Mode Universal Filters. Applied Electronics, Pilsen, 9, 127-130.

[6] Shah, N.A., Rather, M.F. and Iqbal, S.Z. (2005) A Novel Voltage-Mode Universal Filter Using A Single CFA. Active and Passive Electronic Devices, 1, 183-188.

[7] Horng, J.W., Chang, C.K. and Chu, J.M. (2002) Voltage-Mode Universal Biquadratic Filter Using Single Current-Feedback Amplifier. IEICE Transactions on Fundamentals, 85, 1970-1973.

[8] Singh, G., Prasad, D. and Bhaskar, D. (2015) Single VDVTA-Based Voltage-Mode Biquad Filter. Circuits and Systems, 6, 55-59. https://doi.org/10.4236/cs.2015.63006

[9] Herencsar, N., Koton, J. and Vrba, K. (2011) KHN-Equivalent Voltage-Mode Filters Using Universal Voltage Conveyors. AEU-International Journal of Electronics and Communications, 65, 154-160. https://doi.org/10.1016/j.aeue.2010.02.005

[10] Minarcik, M. and Vrba, K. (2007) Continuous-Time Multifunctional Filters with Wide Bandwidth Using Universal Voltage Conveyors. Proceedings of the Sixth International Conference on Networking, Washington, DC, 22-28 April 2007. https://doi.org/10.1109/ICN.2007.32

[11] Minarcik, M. and Vrba, K. (2006) Low-Output and High-Input Impedance Frequency Filters Using Universal Voltage Conveyor for High-Speed Data Communication Systems. International Conference on Networking, International Conference on Systems and International Conference on Mobile Communications and Learning Technologies, 23-29 April 2006, 155.

[12] Herencsar, N., Koton, J., Jerabek. J., Vrba, K. and Cicekoglu, O. (2011) Voltage-Mode All Pass Filter Using Universal Voltage Conveyor and MOSFET-Based Electronic Resistors. Radioengineering, 20, 10-18.

[13] Herencsar, N., Koton, J. and Vrba, K. (2009) A New Electronically Tunable Voltage-Mode Active-C Phase Shifter Using UVC and OTA. IEICE Electronics Express, 6, 1212-1218. https://doi.org/10.1587/elex.6.1212

[14] Sponar, R. and Vrba, K. (2006) Measurements and Behavioral Modeling of Modern Conveyors. International Journal of Computer Science and Network Security, 6, 57-65.

[15] Herencsar, N., Koton, J., Vrba, K. and Minaei, S. (2011) Electronically Tunable MOSFET-C Voltage-Mode All Pass Filter Based on Universal Voltage Conveyor. 
Communication Software and Networks, 442-445.

https://doi.org/10.1109/ICCSN.2011.6014931

[16] Minaei, S. and Yuce, E. (2010) Novel Voltage-Mode All-Pass Filter Based on Using DVCCs. Circuits System and Signal Processing, 29, 391-402.

https://doi.org/10.1007/s00034-010-9150-3

Submit or recommend next manuscript to SCIRP and we will provide best service for you:

Accepting pre-submission inquiries through Email, Facebook, LinkedIn, Twitter, etc. A wide selection of journals (inclusive of 9 subjects, more than 200 journals) Providing 24-hour high-quality service User-friendly online submission system Fair and swift peer-review system Efficient typesetting and proofreading procedure Display of the result of downloads and visits, as well as the number of cited articles Maximum dissemination of your research work

Submit your manuscript at: http://papersubmission.scirp.org/

Or contact cs@scirp.org 